\title{
Atypicality of Atypical Antipsychotics
}

\author{
Andrew Farah, M.D.
}

Objective: To review the current definition of atypicality, discuss the unique features of each atypical antipsychotic, and determine whether the available drugs in this class really meet the classical definition of atypicality.

Data Sources: A PubMed search was conducted to identify literature on the subject of this review, supported by additional articles based on the author's clinical knowledge and experience.

Study Selection and Data Extraction: Relevant references were extracted and summarized in order to meet the objective of the article.

Data Synthesis: Atypical antipsychotics are considered a major advance over conventional antipsychotics, primarily because they offer effective treatment alternatives that are relatively free of extrapyramidal symptoms. In fact, the term atypicality was originally used to describe antipsychotic agents with a minimal risk of causing extrapyramidal symptoms. However, over the years the definition has been modified such that there is currently no consensus on a true definition of atypicality for these agents. Each of the atypical antipsychotics (clozapine, risperidone, olanzapine, quetiapine, ziprasidone, and aripiprazole) commercially available in the United States is unique in terms of its pharmacologic profile, differing with respect to receptor-binding affinity, mechanism of action, and adverse events. Of the available atypical antipsychotics, clozapine and quetiapine have shown the lowest propensity to cause extrapyramidal symptoms. Although the risk of extrapyramidal symptoms is lower with risperidone and olanzapine than with conventional antipsychotics, risk increases with dose escalation. Data for ziprasidone indicate that the risk of extrapyramidal symptoms may be similar to that of risperidone and olanzapine. There is a concern of akathisia with aripiprazole; however, more experience with this agent is needed before definitive conclusions are made.

Conclusion: If the definition of "atypical" antipsychotic is considered to be freedom from extrapyramidal symptoms, then, based on a comprehensive review of available data and clinical experience, clozapine and quetiapine appear to be the only true atypicals.

(Prim Care Companion J Clin Psychiatry 2005;7:268-274)

Received April 19, 2005; accepted July 15, 2005. From High Point Regional Health Systems, High Point, N.C., and the Department of Psychiatry, Wake Forest University, Winston-Salem, N.C.

Editorial support was provided by AstraZeneca Pharmacenticals $L P$. Dr. Farah has participated in speakers/advisory boards for AstraZeneca, Pfizer, Janssen, and Forest Labs.

Corresponding author and reprints: Andrew Farah, M.D., Chief of Psychiatry, High Point Regional Health Systems, 320 Boulevard Street, High Point,NC 27262 (e-mail: afarah@hprhs.com).
$\mathbf{T}$ he development of atypical antipsychotics was an important milestone in the history of psychiatry, because it brought effective treatment options with a reduced risk for adverse events. In particular, the atypical antipsychotics appear to be much less likely to cause extrapyramidal symptoms (EPS), a group of movement disorders associated with physical disability and subjective discomfort and distress, including parkinsonism, akathisia, dystonia, and tardive dyskinesia (a long-term manifestation of EPS). ${ }^{1}$

Atypical antipsychotics were originally defined by a reduced risk of EPS as an adverse event. However, as more atypical antipsychotic agents were introduced, marketing efforts and recent literature modified the definition. Furthermore, it is now unclear whether atypicality should be a clinical distinction (related to EPS or negative symptom relief), a chemical distinction (receptor profile), or a mixture of both.

The purpose of this article is to review the current definition of atypicality, discuss the unique features of each atypical antipsychotic, and determine whether the available drugs in this class really meet the classical definition of atypicality. A PubMed search was conducted to identify literature on the subject of this review, supported by additional articles based on the author's clinical knowledge and experience. Relevant references were extracted and summarized in order to meet the objective of the article.

\section{DEFINITION OF ATYPICALITY}

There is currently no consensus on a true definition of atypicality for antipsychotic medications. Originally, the term was used to describe effective antipsychotic agents associated with a minimal risk of causing EPS., ${ }^{2,3}$ However, as described in reviews by Markowitz et al. ${ }^{2}$ and Goldstein, ${ }^{4}$ a broader definition of atypicality is used today. In addition to a reduced risk of EPS, other elements thought to contribute to atypicality include the following: transient elevation in prolactin levels, efficacy in treating both positive and negative symptoms of schizophrenia, a mechanism of action that involves serotonin (5-HT)-2A and $-2 \mathrm{C}$ antagonism and/or mesolimbic specificity over nigrostriatal dopamine neurons, and efficacy in treatmentresistant schizophrenia. ${ }^{2,4}$ At times, various combinations of these descriptions have served to define atypicality.

Several types of dopamine receptors exist in various regions of the human brain (Table 1). ${ }^{5}$ Psychosis is be- 


\begin{tabular}{lc}
\hline \multicolumn{2}{l}{ Table 1. Dopamine Receptors } \\
\hline Receptor Type & Location \\
\hline $\mathrm{D}_{1}$ & Cortex and basal ganglia \\
$\mathrm{D}_{2}$ & Striatum \\
$\mathrm{D}_{3}$ & Limbic region \\
$\mathrm{D}_{4}$ & Limbic region \\
${ }^{\mathrm{a}}$ Based on Beng-Choon et al. & \\
\hline
\end{tabular}

lieved to result from excess dopamine in the mesolimbic and/or mesocortical regions of the brain, but blockade of dopamine in the striatum of the brain can result in adverse events, such as parkinsonian symptoms and hyperprolactinemia ${ }^{6,7}$ All clinically effective antipsychotics at least partially antagonize the dopamine-2 $\left(D_{2}\right)$ receptor. However, the degree of $\mathrm{D}_{2}$-receptor affinity differs and is thought to serve as a predictor of adverse events such as EPS (including akathisia). ${ }^{4,8}$ Data from positron emission tomography (PET) studies evaluating $\mathrm{D}_{2}$ occupancy by antipsychotics indicate that thresholds of $65 \%, 72 \%$, and $78 \%$ are associated with clinical efficacy, hyperprolactinemia, and EPS, respectively. ${ }^{9}$

All antipsychotics launched after clozapine have been categorized as atypical, regardless of their $\mathrm{D}_{2}$ affinity or propensity to cause EPS, although not all compounds so classified meet the aforementioned criteria of transient prolactin elevation, 5-HT-2A and -2C antagonism, mesolimbic specificity, and efficacy in treating positive and negative symptoms and in treatment-resistant schizophrenia. Unlike classes of medication such as conventional antipsychotics or serotonin reuptake inhibitors, antipsychotics categorized as atypical do not share, even in a broad sense, the same general pharmacologic profile as other members of their class. For example, the atypical antipsychotics differ with respect to receptor-binding affinity (Table 2$),{ }^{10-13}$ proposed mechanism of action, and adverse event profile.

\section{ATYPICAL ANTIPSYCHOTICS}

There are 6 atypical antipsychotics commercially available in the United States: clozapine, risperidone, olanzapine, quetiapine, ziprasidone, and aripiprazole. Compared with the conventional antipsychotics, the atypicals have a lower propensity to induce EPS and tardive dyskinesia and have a broader spectrum of efficacy (e.g., greater improvements in negative, depressive, and cognitive symptoms). ${ }^{14}$ In a review of 11 long-term antipsychotic trials lasting at least 1 year, ${ }^{15}$ the weighted mean annual incidence risk of tardive dyskinesia was $2.1 \%$ among patients receiving an atypical antipsychotic regardless of age group compared with $5.4 \%$ for adult patients receiving haloperidol ( 3 studies, mean dose $=13.1 \mathrm{mg} /$ day). The estimated risk of tardive dyskinesia among individual atypical antipsychotics varied, with reported rates of $0 \%$ to $0.5 \%$ for olanzapine ( 2 studies, mean dose $=13.6 \mathrm{mg} /$ day $), 0.6 \%$ to $0.7 \%$ for risperidone $(5$ studies, mean dose $=2.7 \mathrm{mg} / \mathrm{day}$ orally or $55.2 \mathrm{mg} / 14$ days intravenous) and quetiapine (2 studies, mean dose $=408.3 \mathrm{mg} / \mathrm{day}$ ), and $6.8 \%$ for ziprasidone ( 1 study, mean dose $=92 \mathrm{mg} /$ day ).

Differences exist between the atypicals with regard to weight gain, hyperprolactinemia, sedation, sexual dysfunction, and anticholinergic and metabolic adverse events. The effects of antipsychotic treatment on the development of metabolic disorders are gradually emerging. Currently, warnings about hyperglycemia and diabetes mellitus are contained in the U.S. prescribing information for each of these agents. ${ }^{10,11,16-19}$ Cerebrovascular adverse events were first reported with risperidone. ${ }^{20}$ However, a warning regarding cerebrovascular adverse events in patients with dementia-related psychosis was recently added to the U.S. prescribing information for aripiprazole, olanzapine, and risperidone..$^{10,17,19}$ The following sections discuss the differences with regard to atypicality among these agents.

\section{Clozapine}

Clozapine was the first atypical antipsychotic approved for use in the United States, although it is now reserved for severely ill patients with schizophrenia and those with schizophrenia or schizoaffective disorder at risk for suicidal behavior. ${ }^{16}$ It is classified as a dibenzothiazepine derivative and is known to be particularly effective in patients who do not respond to conventional or other atypical antipsychotics. ${ }^{16,21}$ The effective dosage range is 300 to $600 \mathrm{mg} / \mathrm{day}$, but dosages of up to $900 \mathrm{mg}$ /day may be needed in some patients. ${ }^{16}$

Clozapine fits all of the proposed definitions of atypicality. It has a low propensity for causing EPS after acute administration, does not produce tardive dyskinesia with long-term administration, and does not elevate plasma prolactin levels. ${ }^{4}$ Imaging studies have shown a correlation between negative symptoms and reduced prefrontal blood flow ${ }^{22}$ and glucose metabolism. ${ }^{23}$ In a report of a patient with first-episode schizophrenia, clozapine was shown to reverse hypofrontality, which may be the mechanism by which negative symptoms are improved. ${ }^{22}$

The affinity of clozapine for $\mathrm{D}_{2}$ receptors is below the threshold that is predictive of EPS and hyperprolactinemia. At doses of 125 to $600 \mathrm{mg}$, clozapine has a $\mathrm{D}_{2}$ occupancy of $20 \%$ to $67 \%,{ }^{24}$ although dissociation appears to be rapid. ${ }^{25}$ In addition to $\mathrm{D}_{2}$ receptor blockade, clozapine shows high affinity for $\mathrm{D}_{1}$ receptors and antagonism for $\mathrm{D}_{3}$ and $\mathrm{D}_{4}$ subtypes. ${ }^{26}$ Although activity at these receptors is not characteristic of atypicality, it may be important for antipsychotic activity ${ }^{26}$ (although quetiapine is an effective antipsychotic that has virtually no affinity for $\mathrm{D}_{4}$ receptors). Data from Nordstrom et al. ${ }^{24}$ indicate that at doses of 300 to $600 \mathrm{mg}$, clozapine has a $\mathrm{D}_{1}$ occupancy of $33 \%$ to $59 \%$. The affinity of clozapine for 5-HT receptors is also high, with a $5-\mathrm{HT}_{2}$ receptor occupancy of $84 \%$ to $94 \%$ at doses of 125 to $400 \mathrm{mg} .^{24}$ 


\begin{tabular}{|c|c|c|c|c|c|c|}
\hline$\underline{\text { Receptor }}$ & $\begin{array}{c}\text { Clozapine } \\
\left(\mathrm{K}_{\mathrm{i}}, \mathrm{nM}\right)\end{array}$ & $\begin{array}{c}\text { Risperidone } \\
\left(\mathrm{K}_{\mathrm{i}}, \mathrm{nM}\right)\end{array}$ & $\begin{array}{c}\text { Olanzapine } \\
\left(\mathrm{K}_{\mathrm{i}}, \mathrm{nM}\right)\end{array}$ & $\begin{array}{l}\text { Quetiapine } \\
\left(\mathrm{IC}_{50}, \mathrm{nM}\right) \\
\end{array}$ & $\begin{array}{c}\text { Ziprasidone } \\
\left(\mathrm{K}_{\mathrm{i}}, \mathrm{nM}\right)\end{array}$ & $\begin{array}{c}\text { Aripiprazole } \\
\left(\mathrm{K}_{\mathrm{i}}, \mathrm{nM}\right) \\
\end{array}$ \\
\hline $\mathrm{D}_{1}$ & 85 & 75 & 31 & 1268 & - & - \\
\hline$D_{2}$ & 125 & 3 & 11 & 329 & 4.8 & 0.34 \\
\hline $5-\mathrm{HT}_{1 \mathrm{~A}}$ & 770 & 490 & $>1000$ & 717 & 3.4 & 1.7 \\
\hline $5-\mathrm{HT}_{1 \mathrm{D}}$ & 980 & 100 & 800 & - & 2 & - \\
\hline $5-\mathrm{HT}_{2 \mathrm{~A}}$ & 12 & 0.6 & 4 & 148 & 0.4 & 3.4 \\
\hline $5-\mathrm{HT}_{2 \mathrm{C}}$ & 8 & 26 & 11 & - & 1.3 & 15 \\
\hline$\alpha_{1}$ & 7 & 2 & 19 & 94 & 10 & 57 \\
\hline $\mathrm{H}_{1}$ & 6 & 155 & 7 & 30 & 47 & 61 \\
\hline$\underline{\mathrm{M}_{1}}$ & 1.9 & $>10,000^{c}$ & 1.9 & $>10,000$ & $>10,000^{c}$ & $>1000^{c}$ \\
\hline \multicolumn{7}{|c|}{ 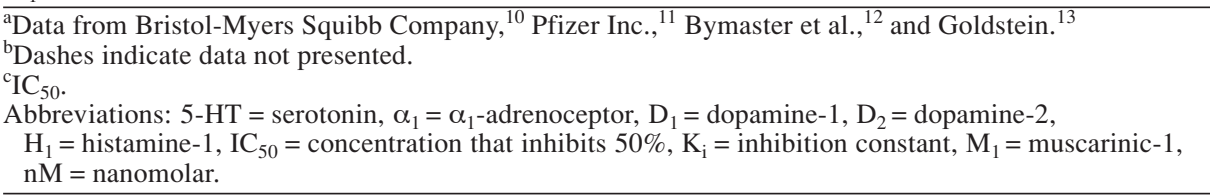 } \\
\hline
\end{tabular}

The use of clozapine is primarily limited by the risk of agranulocytosis, defined as a granulocyte count of $<500 / \mathrm{mm}^{3} .^{21}$ Data collected from more than $11,000 \mathrm{pa}$ tients through the Clozaril Patient Management System indicate that the incidence of agranulocytosis was $0.80 \%$ at 1 year. ${ }^{27}$ In general, agranulocytosis appears to occur within the first 3 months of therapy, with the risk peaking by the third month. ${ }^{27}$ Gaszner et al. ${ }^{28}$ reported a prevalence of $1 \%$ for granulocytopenia and $0.26 \%$ for agranulocytosis among a group of 750 patients who received clozapine therapy for schizophrenia or schizoaffective psychosis over a period of 15 years. These authors suggest that, with proper management, blood dyscrasias induced by clozapine appear to be reversible and not life threatening.

Other adverse events of significant concern in patients receiving clozapine include weight gain, risk of seizures, myocarditis, pancreatitis, and orthostatic hypotension with or without syncope. With regard to weight, a meta-analysis evaluating 10 weeks of therapy with 4 of the 6 commercially available atypical antipsychotics showed a mean increase in weight of $4.45 \mathrm{~kg}$ with clozapine, the greatest increase among the atypicals studied. ${ }^{29}$ Myocarditis appears to be a rare but serious adverse event. ${ }^{30}$ Postmarketing data for clozapine indicate that the risk of myocarditis appears to be greatest during the first month of therapy but may occur at other times. ${ }^{16}$ In an analysis of an international database on adverse drug reactions maintained by the World Health Organization, examination of the relationship between antipsychotics and myocarditis and cardiomyopathy using Bayesian statistics suggests that these symptoms are strongly associated with clozapine use..$^{31}$ As a result, it is recommended that clozapine be promptly discontinued in patients suspected of having myocarditis.

\section{Risperidone}

Risperidone is classified as a benzisoxazole derivative and is indicated for the treatment of schizophrenia and acute manic or mixed episodes associated with bipolar disorder. ${ }^{17}$ It is widely used and is effective, along with its pri- mary metabolite 9-hydroxyrisperidone. The dosage range for risperidone is 2 to $16 \mathrm{mg} /$ day. Based on clinical experience, the majority of responders require $6 \mathrm{mg} /$ day or less of risperidone.

Of the atypical antipsychotics, risperidone is the weakest in terms of atypicality criteria. Although early clinical studies with risperidone indicated that the incidence of EPS is not greater than that seen with placebo, this may not be the case. Dose-dependent EPS have been reported in $60 \%$ to $70 \%$ of patients taking risperidone at dosages of $\geq 6 \mathrm{mg} /$ day. $^{3}$ In a prospective study of 350 antipsychotic-naive patients, those treated with low-dose risperidone had a similar high incidence of movement disorders as those who received low-dose haloperidol. ${ }^{32}$ Numerous case reports of dystonic reactions and tardive dyskinesia with risperidone also have appeared in the literature. ${ }^{33-40}$ In addition, risperidone is more likely than other atypicals to cause persistently elevated prolactin levels. ${ }^{4,41,42}$ Risperidone also is associated with a moderate risk of weight gain (1.69-2.51 kg) following 10 weeks of treatment ${ }^{29}$ and orthostatic hypotension and a mild risk of somnolence. ${ }^{14}$

In a study of $\mathrm{D}_{2}$ occupancy in individuals receiving risperidone doses of 2,4 , and $6 \mathrm{mg}$, the mean level of $\mathrm{D}_{2}$-receptor occupancy was $66 \%$ at $2 \mathrm{mg}, 73 \%$ at $4 \mathrm{mg}$, and $79 \%$ at $6 \mathrm{mg} .{ }^{43} \mathrm{D}_{2}$-receptor occupancy of risperidone at doses of $\geq 4 \mathrm{mg}$ is above the threshold associated with EPS and hyperprolactinemia. ${ }^{43,44}$ Risperidone is able to occupy $\mathrm{D}_{2}$ receptors gradually, which is not a property shared with the conventional antipsychotics or olanzapine. ${ }^{45}$ Occupancy of $5-\mathrm{HT}_{2}$ receptors has been shown to be $>95 \%$ with risperidone at dosages of 2 to $4 \mathrm{mg} / \mathrm{day} .{ }^{8}$

\section{Olanzapine}

Olanzapine belongs to the thienobenzodiazepine class of psychotropic agents. It is indicated for the treatment of schizophrenia and is currently the only atypical antipsychotic approved for use in both acute and maintenance therapy of mixed or manic episodes associated with bi- 
polar I disorder. ${ }^{19}$ The approved dosage range of olanzapine is 10 to $15 \mathrm{mg} / \mathrm{day}$ for schizophrenia and 5 to 20 $\mathrm{mg} /$ day for bipolar disorder.

The atypicality of olanzapine is questionable and appears to fall between that of clozapine and risperidone. Olanzapine generally has a mild-to-minimal risk of causing EPS and hyperprolactinemia ${ }^{14}$; however, the risk is dose-dependent. In a study evaluating the $\mathrm{D}_{2}$ and 5- $\mathrm{HT}_{2}$ occupancy of olanzapine,${ }^{46}$ EPS and hyperprolactinemia were noted to occur in patients treated with olanzapine at dosages of $>20 \mathrm{mg} /$ day. In this study, $\mathrm{D}_{2}$ occupancy was $55 \%$ at $5 \mathrm{mg} / \mathrm{day}, 73 \%$ at $10 \mathrm{mg} / \mathrm{day}, 75 \%$ at $15 \mathrm{mg} / \mathrm{day}$, $76 \%$ at $20 \mathrm{mg} / \mathrm{day}, 83 \%$ at $30 \mathrm{mg} /$ day, and $88 \%$ at 40 $\mathrm{mg} /$ day. The $5-\mathrm{HT}_{2}$ receptor occupancy was greater than $90 \%$ at all olanzapine doses studied.

With the exception of clozapine, olanzapine has been associated with a higher degree of weight gain than other available atypical antipsychotics. ${ }^{14,47}$ At 10 weeks, olanzapine at standard doses may produce between 4 and $4.5 \mathrm{~kg}$ of weight gain. Weight gain with olanzapine does not appear to be dose related within the therapeutic dosage range of 5 to $20 \mathrm{mg} / \mathrm{day}$, and weight changes tend to plateau at 7 to $8 \mathrm{~kg}$ after about 40 weeks of treatment. ${ }^{47}$ Olanzapine is also associated with a moderate risk of transient somnolence. ${ }^{14}$ Unlike the other atypical antipsychotics, the oral clearance of olanzapine is increased by smoking (cytochrome P450 1A2 [CYP1A2] inducers) and may require dosage adjustments in some patients. ${ }^{19}$ This is a significant interaction, given that different surveys have shown that $58 \%$ to $90 \%$ of patients with schizophrenia smoke (vs. $28 \%-30 \%$ of the general U.S. population). ${ }^{48}$

\section{Quetiapine}

Quetiapine is similar in structure to clozapine (but derived from perlapine) and as such is classified as a dibenzothiazepine derivative. It is indicated for the treatment of schizophrenia and acute manic episodes associated with bipolar I disorder. ${ }^{18}$ The clinically effective dosage range for both bipolar I disorder and schizophrenia is 400 to 800 $\mathrm{mg} /$ day, although more severe cases may require higher dosages.

Clinical data indicate that quetiapine is associated with levels of EPS similar to those of placebo across the dosage range and is not associated with elevations in prolactin levels. ${ }^{4,49}$ It has been suggested that the atypicality of quetiapine may be explained by its ability to transiently occupy $\mathrm{D}_{2}$ receptors. ${ }^{4}$ This characteristic, unique only to quetiapine and clozapine, permits modest occupancy at the $\mathrm{D}_{2}$ receptors that rapidly declines to minimal levels 12 to 24 hours after the last dose. ${ }^{4,25,50}$ Like clozapine, quetiapine has a higher relative affinity for $5-\mathrm{HT}_{2 \mathrm{~A}}$ receptors than $\mathrm{D}_{2}$ receptors. In a PET imaging study evaluating the $\mathrm{D}_{2}$ and $5-\mathrm{HT}_{2}$ occupancy of quetiapine at dosages of 150 to $600 \mathrm{mg} /$ day, quetiapine was found to have minimal $\mathrm{D}_{2}$ occupancy $(0 \%-27 \%)$ and high $5-\mathrm{HT}_{2}$ occupancy
$(19 \%-94 \%) 12$ hours after the last dose. ${ }^{50}$ Thus, the low $\mathrm{D}_{2}$ occupancy of quetiapine combined with its ability to transiently occupy these receptors may explain the very low risk of EPS with this agent. ${ }^{4}$ Antipsychotic effects are achieved with rapid but transient binding $\left(58 \%-64 \% \mathrm{D}_{2}\right.$ occupancy at 2-3 hours after a dose, declining to minimal occupancy by the end of a 12-hour dosing interval). ${ }^{50}$ This transient binding appears to be sufficient for clinical efficacy of quetiapine, ${ }^{50}$ while never approaching the $78 \%$ threshold of $D_{2}$ occupancy necessary for EPS.

Quetiapine has a greater affinity for $\alpha_{1}$-adrenergic and histamine-1 receptors than for $\mathrm{D}_{2}$ receptors. As a result, patients taking quetiapine may be at risk for orthostatic hypotension and transient sedation. ${ }^{4}$ In clinical practice, the risk of sedation appears to be greater than that of orthostatic hypotension, provided patients are appropriately monitored. In a retrospective analysis of the quetiapine safety database consisting of data from 77 clinical studies, $25.5 \%$ of patients (2013/7894) reported somnolence at least once during quetiapine therapy. ${ }^{51}$ In this analysis, somnolence was of mild intensity and occurred in the first week of therapy, with a decrease over time such that, by week 4 , the first onset of somnolence was reported in $<1 \%$ of patients receiving the medication. Quetiapine has been reported to be associated with a $1.58 \mathrm{-kg}$ mean increase in weight following 9 to 13 weeks of therapy. ${ }^{52}$

\section{Ziprasidone}

Ziprasidone is a structural analog of risperidone and as such is classified as a benzisoxazole derivative. It is indicated for the treatment of schizophrenia and acute manic or mixed episodes associated with bipolar disorder with or without psychotic features. ${ }^{11}$ The effective dosage range for ziprasidone is 80 to $160 \mathrm{mg} / \mathrm{day}$. In our clinical experience with this medication, only about one quarter of patients are responsive; however, because of its ability to antagonize 5- $\mathrm{HT}_{1 \mathrm{~A}}$ and its high affinity for other 5-HT receptors, it has the potential to reduce depressive symptoms. ${ }^{4}$

Controlled clinical trials suggest that ziprasidone is associated with a low risk of EPS and transient but nondose-related elevations in prolactin. ${ }^{53-55}$ However, anecdotal experience suggests that the occurrence of EPS during ziprasidone therapy may be more prominent than clinical trials indicate. Unlike clozapine or quetiapine, ziprasidone has a high affinity for $\mathrm{D}_{2}$ receptors and a very high affinity for $5-\mathrm{HT}_{2}$ receptors. ${ }^{4}$ Despite the high affinity for $\mathrm{D}_{2}$ receptors, it has been suggested that its higher affinity for 5-HT ${ }_{2 \mathrm{~A}}$ receptors may limit the occurrence of EPS. ${ }^{56}$

In a PET study evaluating the $\mathrm{D}_{2}$ and $5-\mathrm{HT}_{2}$ receptor occupancy of ziprasidone at dosages of 40,60, 80, and 160 $\mathrm{mg} /$ day,${ }^{57}$ the mean $5-\mathrm{HT}_{2}$ receptor occupancy $(76 \%$; range, 52\%-99\%) was significantly higher than the mean $\mathrm{D}_{2}$ receptor occupancy (56\%; range, $\left.10 \%-73 \%\right)$. Because the relationship between $\mathrm{D}_{2}$ and $5-\mathrm{HT}_{2}$ receptor occupancy 
and plasma ziprasidone levels was significantly positively correlated, the authors were able to predict that the maximum $\mathrm{D}_{2}$ receptor occupancy of ziprasidone would be $84 \%$. These findings suggest that the relatively high $\mathrm{D}_{2}$ occupancy (maximum $73 \%$; predicted maximum $84 \%$ ) observed with ziprasidone in this study is more similar to that of risperidone and olanzapine than that of clozapine and quetiapine.

Ziprasidone has been reported to be associated with a mild risk of orthostatic hypotension, sedation, and QT prolongation. ${ }^{14}$ Concern over QT prolongation and the risk of sudden death was a significant issue for ziprasidone when it was first approved to market and led to numerous investigations of the cardiac safety of antipsychotics. Although a warning for QT prolongation and risk of sudden death remains in the product label for ziprasidone, ${ }^{11}$ excessive concern appears to be unfounded. ${ }^{58}$ QTc interval change occurs with countless psychotropic medications and on the whole is minimal, highly variable from patient to patient, and only of major concern in cardiac patients and those already taking agents known to prolong QTc. Although data with ziprasidone are limited, weight gain appears to be minimal $(0.04 \mathrm{~kg})$ over the course of 10 weeks, ${ }^{29}$ and ziprasidone is associated with a small loss in weight indistinguishable from that seen with placebo over the course of 1 year. ${ }^{59}$

\section{Aripiprazole}

Aripiprazole differs from the other atypical antipsychotics in that it is a partial agonist at $\mathrm{D}_{2}$ and $5-\mathrm{HT}_{1 \mathrm{~A}}$ receptors and has antagonistic activity at $5-\mathrm{HT}_{2 \mathrm{~A}}$ and $5-\mathrm{HT}_{2 \mathrm{C}}$ receptors. ${ }^{60,61} \mathrm{It}$ is indicated for the treatment of schizophrenia and acute manic and mixed episodes associated with bipolar disorder and has an effective dosage range of 10 to $30 \mathrm{mg} /$ day. $^{10,62,63}$

Clinical data suggest that the occurrence of EPS with aripiprazole is similar to that with placebo, and it does not appear to elevate prolactin levels. ${ }^{10,60}$ However, EPS and akathisia have been reported to occur during aripiprazole therapy. ${ }^{10,64,65}$

In a PET study evaluating aripiprazole 0.5 to 30 $\mathrm{mg} /$ day in 15 healthy subjects, a dose response in $\mathrm{D}_{2}$ - and $\mathrm{D}_{3}$-receptor occupancy was found. Receptor occupancy increased from below $40 \%$ at $0.5 \mathrm{mg}$ to over $90 \%$ at 30 $\mathrm{mg} /$ day ${ }^{66}$ These results suggest that administration of high doses of aripiprazole would lead to an increased risk of EPS; however, no EPS were observed in patients receiving high doses $(30 \mathrm{mg} /$ day) of aripiprazole in this study. The authors suggest that the lack of EPS may have to do with the partial agonistic activity of aripiprazole. ${ }^{66}$ However, in clinical trials evaluating aripiprazole for the treatment of schizophrenia and bipolar mania, akathisia has been reported..$^{10,62}$ At this time, the data are too limited to draw definitive conclusions regarding the EPS profile of aripiprazole.
Meta-analyses suggest that the most common adverse events (prevalence $\geq 10 \%$ and $\geq$ placebo) associated with aripiprazole include headache, anxiety, insomnia, nausea, vomiting, light-headedness, somnolence, constipation, and akathisia. ${ }^{60}$ In short-term trials, aripiprazole was associated with a $15 \%$ incidence of akathisia (compared with $4 \%$ with placebo) in patients with bipolar mania and a $0.71-\mathrm{kg}$ increase in weight (compared with a $0.05-\mathrm{kg}$ decrease with placebo) in patients with schizophrenia. ${ }^{10,60}$

\section{DISCUSSION}

Antipsychotics are prescribed for a wide range of conditions. In addition to being the standard of care for psychosis, atypical antipsychotics are prescribed more than $70 \%$ of the time outside the FDA-approved labeling for patients with nonpsychotic conditions (e.g., anxiety disorder and mood stability in bipolar disorder). ${ }^{67}$ Because primary care physicians are likely to prescribe an antipsychotic or see patients receiving these medications, it is important that they are aware of the differences that exist among the various atypical antipsychotics.

The main reason for the development of atypical antipsychotics was to provide an antipsychotic treatment option that was free of EPS and, further, to reduce the risk of tardive dyskinesia. Although many agents now claim to be atypical, the data presented suggest that only clozapine and quetiapine are true atypical antipsychotics. Of the available agents, clozapine and quetiapine show the lowest affinity for and the most rapid release from $\mathrm{D}_{2}$ receptors. ${ }^{3}$ As a result, clozapine and quetiapine have been shown to have an incidence of EPS that was no different from placebo across the full dosage range. ${ }^{4}$

Promotion of risperidone, olanzapine, ziprasidone, and possibly aripiprazole has emphasized the atypicality of these agents; however, based on the data presented here, one should question whether these agents are truly atypical antipsychotics. Both risperidone and olanzapine have demonstrated EPS levels similar to placebo at low doses; at higher doses, however, EPS incidence for both agents becomes greater than with placebo. ${ }^{4}$ Data for ziprasidone are limited; however, ziprasidone appears to have an EPS risk similar to that of risperidone and olanzapine. ${ }^{56,57}$ Aripiprazole has been associated with akathisia; however, further study and experience with this drug are needed before definitive conclusions can be drawn.

\section{CONCLUSION}

A review of the pharmacologic and clinical information to date for all available antipsychotics would indicate that quetiapine and clozapine are the only "true" atypicals when one considers $\mathrm{D}_{2}$-receptor activity, propensity toward EPS, and, by correlation, risk for tardive dyskinesia. Other agents cannot be considered atypical by this defini- 
tion, particularly if used in doses that cause EPS in general or akathisia in particular. Clinicians must consider the true definition of "atypical antipsychotic" when prescribing a newer agent and must ultimately be satisfied with the short-term and long-term safety of that agent.

Drug names: aripiprazole (Abilify), clozapine (Clozaril, FazaClo, and others), haloperidol (Haldol and others), olanzapine (Zyprexa), quetiapine (Seroquel), risperidone (Risperdal), ziprasidone (Geodon).

\section{REFERENCES}

1. Kane JM. Extrapyramidal side effects are unacceptable. Eur Neuropsychopharmacol 2001;11(suppl 4):S397-S403

2. Markowitz JS, Brown CS, Moore TR. Atypical antipsychotics, pt 1: pharmacology, pharmacokinetics, and efficacy. Ann Pharmacother 1999;33:73-85

3. Seeman P. Atypical antipsychotics: mechanism of action. Can J Psychiatry 2002;47:27-38

4. Goldstein JM. The new generation of antipsychotic drugs: how atypical are they? Int J Neuropsychopharmacol 2000;3:339-349

5. Beng-Choon H, Black D, Andreasen NC. Schizophrenia and other psychotic disorders. In: Hales R, Yudofsky S, eds. Textbook of Clinical Psychiatry, Fourth Edition. Washington, DC: American Psychiatric Publishing, Inc; 2003:379-438

6. Reynolds GP. What is an atypical antipsychotic? J Psychopharmacol 1997;11:195-199

7. Compton MT, Miller AH. Antipsychotic-induced hyperprolactinemia and sexual dysfunction. Psychopharmacol Bull 2002;36:143-164

8. Kapur S, Zipursky RB, Remington G. Clinical and theoretical implications of 5-HT2 and D2 receptor occupancy of clozapine, risperidone, and olanzapine in schizophrenia. Am J Psychiatry 1999;156:286-293

9. Kapur S, Zipursky R, Jones C, et al. Relationship between dopamine $\mathrm{D}(2)$ occupancy, clinical response, and side effects: a double-blind PET study of first-episode schizophrenia. Am J Psychiatry 2000;157: 514-520

10. Abilify (aripiprazole). Full Prescribing Information. Princeton, NJ: Bristol-Myers Squibb Company; 2005

11. Geodon (ziprasidone). Full Prescribing Information. New York, NY: Pfizer Inc; 2005

12. Bymaster FP, Calligaro DO, Falcone JF, et al. Radioreceptor binding profile of the atypical antipsychotic olanzapine. Neuropsychopharmacology 1996;14:87-97

13. Goldstein J. Preclinical profile of Seroquel (quetiapine): an atypical antipsychotic with clozapine-like pharmacology. In: Holliday SG, Ancill RJ, MacEwen GW, eds. Schizophrenia: Breaking Down the Barriers. Hoboken, NJ: John Wiley and Sons Ltd; 1996:177-208

14. Tandon R. Safety and tolerability: how do newer generation "atypical" antipsychotics compare? Psychiatr Q 2002;73:297-311

15. Correll CU, Leucht S, Kane JM. Lower risk for tardive dyskinesia associated with second-generation antipsychotics: a systematic review of 1-year studies. Am J Psychiatry 2004;161:414-425

16. Clozaril (clozapine). Full Prescribing Information. East Hanover, NJ: Novartis Pharmaceuticals Corporation; 2003

17. Risperdal (risperidone). Full Prescribing Information. Titusville, NJ: Janssen Pharmaceutica; 2005

18. Seroquel (quetiapine fumarate). Full Prescribing Information. Wilmington, Del: AstraZeneca Pharmaceuticals LP; 2004

19. Zyprexa (olanzapine). Full Prescribing Information. Indianapolis, Ind: Eli Lilly and Company; 2005

20. Brodaty H, Ames D, Snowdon J, et al. A randomized placebo-controlled trial of risperidone for the treatment of aggression, agitation, and psychosis of dementia. J Clin Psychiatry 2003;64:134-143

21. Iqbal MM, Rahman A, Husain Z, et al. Clozapine: a clinical review of adverse effects and management. Ann Clin Psychiatry 2003;15:33-48

22. Chen RY, Chen E, Ho WY. A five-year longitudinal study of the regional cerebral metabolic changes of a schizophrenic patient from the first episode using Tc-99m HMPAO SPECT. Eur Arch Psychiatry Clin Neurosci 2000;250:69-72

23. Potkin SG, Alva G, Fleming K, et al. A PET study of the pathophysiol- ogy of negative symptoms in schizophrenia. Am J Psychiatry 2002;159: 227-237

24. Nordstrom AL, Farde L, Nyberg S, et al. D1, D2, and 5-HT2 receptor occupancy in relation to clozapine serum concentration: a PET study of schizophrenic patients. Am J Psychiatry 1995;152:1444-1449

25. Kapur S, Seeman P. Does fast dissociation from the dopamine D(2) receptor explain the action of atypical antipsychotics? a new hypothesis. Am J Psychiatry 2001;158:360-369

26. Arnt J, Skarsfeldt T. Do novel antipsychotics have similar pharmacological characteristics? a review of the evidence. Neuropsychopharmacology 1998;18:63-101

27. Alvir JM, Lieberman JA, Safferman AZ, et al. Clozapine-induced agranulocytosis: incidence and risk factors in the United States. N Engl J Med 1993;329:162-167

28. Gaszner P, Makkos Z, Kosza P. Agranulocytosis during clozapine therapy. Prog Neuropsychopharmacol Biol Psychiatry 2002;26:603-607

29. Allison DB, Mentore JL, Heo M, et al. Antipsychotic-induced weight gain: a comprehensive research synthesis. Am J Psychiatry 1999;156: 1686-1696

30. Hagg S, Spigset O, Bate A, et al. Myocarditis related to clozapine treatment. J Clin Psychopharmacol 2001;21:382-388

31. Coulter DM, Bate A, Meyboom RH, et al. Antipsychotic drugs and heart muscle disorder in international pharmacovigilance: data mining study. BMJ 2001;322:1207-1209

32. Rosebush PI, Mazurek MF. Neurologic side effects in neuroleptic-naive patients treated with haloperidol or risperidone. Neurology 1999;52: 782-785

33. Bassitt DP, de Souza Lobo Garcia L. Risperidone-induced tardive dyskinesia. Pharmacopsychiatry 2000;33:155-156

34. Ipekci S, Birsoz S. Tardive dyskinesia caused by the atypical antipsychotic risperidone and cured by the use of another drug of the same class, olanzapine [letter]. Eur Psychiatry 2001;16:259-260

35. Lykouras L, Yannakis R, Hatzimanolis J, et al. Two cases of risperidoneinduced tardive dyskinesia and a review of the literature. Eur Psychiatry 1999;14:245-247

36. Magnuson TM, Roccaforte WH, Wengel SP, et al. Medication-induced dystonias in nine patients with dementia. J Neuropsychiatry Clin Neurosci 2000;12:219-225

37. Narendran R, Young CM, Pato MT. Possible risperidone-induced tardive dystonia [letter]. Ann Pharmacother 2000;34:1487-1488

38. Nelson MW, Reynolds RR, Kelly DL, et al. Adjunctive quetiapine decreases symptoms of tardive dyskinesia in a patient taking risperidone. Clin Neuropharmacol 2003;26:297-298

39. Spivak M, Smart M. Tardive dyskinesia from low-dose risperidone [letter]. Can J Psychiatry 2000;45:202

40. Suzuki E, Obata M, Yoshida Y, et al. Tardive dyskinesia with risperidone and anticholinergics [letter]. Am J Psychiatry 2002;159:1948

41. Halbreich U, Kinon BJ, Gilmore JA, et al. Elevated prolactin levels in patients with schizophrenia: mechanisms and related adverse effects. Psychoneuroendocrinology 2003;28(suppl 1):53-67

42. Kinon BJ, Gilmore JA, Liu H, et al. Hyperprolactinemia in response to antipsychotic drugs: characterization across comparative clinical trials. Psychoneuroendocrinology 2003;28(suppl 2):69-82

43. Kapur S, Remington G, Zipursky RB, et al. The D2 dopamine receptor occupancy of risperidone and its relationship to extrapyramidal symptoms: a PET study. Life Sci 1995;57:PL103-PL107

44. Glazer WM. Extrapyramidal side effects, tardive dyskinesia, and the concept of atypicality. J Clin Psychiatry 2000;61(suppl 3):16-21

45. Schotte A, Janssen PF, Gommeren W, et al. Risperidone compared with new and reference antipsychotic drugs: in vitro and in vivo receptor binding. Psychopharmacology (Berl) 1996;124:57-73

46. Kapur S, Zipursky RB, Remington G, et al. 5-HT2 and D2 receptor occupancy of olanzapine in schizophrenia: a PET investigation. Am J Psychiatry 1998;155:921-928

47. Allison DB, Casey DE. Antipsychotic-induced weight gain: a review of the literature. J Clin Psychiatry 2001;62(suppl 7):22-31

48. Green AI, Salomon MS, Brenner MJ, et al. Treatment of schizophrenia and comorbid substance use disorder. Curr Drug Target CNS Neurol Disord 2002;1:129-139

49. Arvanitis LA, Miller BG, for the Seroquel Trial 13 Study Group. Multiple fixed doses of "Seroquel" (quetiapine) in patients with acute exacerbation of schizophrenia: a comparison with haloperidol and placebo. Biol Psychiatry 1997;42:233-246 
50. Kapur S, Zipursky R, Jones C, et al. A positron emission tomography study of quetiapine in schizophrenia: a preliminary finding of an antipsychotic effect with only transiently high dopamine $\mathrm{D}_{2}$ receptor occupancy. Arch Gen Psychiatry 2000;57:553-559

51. Goldstein J, Zhong K. Tolerance to somnolence with quetiapine ('Seroquel'): preclinical mechanisms and clinical evidence. Presented at the XXIV Collegium Internationale Neuro-Psychopharmacologicum; June 2004; Paris, France

52. Brecher M, Rak IW, Melvin K, et al. The long-term effect of quetiapine ('Seroquel') monotherapy on weight in patients with schizophrenia. Int J Psychiatry Clin Pract 2000;4:287-291

53. Keck P Jr, Buffenstein A, Ferguson J, et al. Ziprasidone 40 and 120 $\mathrm{mg} /$ day in the acute exacerbation of schizophrenia and schizoaffective disorder: a 4-week placebo-controlled trial. Psychopharmacology (Berl) 1998;140:173-184

54. Daniel DG, Zimbroff DL, Potkin SG, et al. Ziprasidone $80 \mathrm{mg} /$ day and $160 \mathrm{mg} /$ day in the acute exacerbation of schizophrenia and schizoaffective disorder: a 6-week placebo-controlled trial. Ziprasidone Study Group. Neuropsychopharmacology 1999;20:491-505

55. Miceli JJ, Wilner KD, Hansen RA, et al. Single- and multiple-dose pharmacokinetics of ziprasidone under non-fasting conditions in healthy male volunteers. Br J Clin Pharmacol 2000;49(suppl 1):5S-13S

56. Tarsy D, Baldessarini RJ, Tarazi FI. Effects of newer antipsychotics on extrapyramidal function. CNS Drugs 2002;16:23-45

57. Mamo D, Kapur S, Shammi CM, et al. A PET study of dopamine D2 and serotonin 5-HT2 receptor occupancy in patients with schizophrenia treated with therapeutic doses of ziprasidone. Am J Psychiatry 2004;161: $818-825$

58. Harrigan EP, Miceli JJ, Anziano R, et al. A randomized evaluation of the effects of six antipsychotic agents on QTc, in the absence and presence of metabolic inhibition. J Clin Psychopharmacol 2004;24:62-69

59. Arato M, O’Connor R, Meltzer HY. A 1-year, double-blind, placebocontrolled trial of ziprasidone 40,80 and $160 \mathrm{mg} /$ day in chronic schizophrenia: the Ziprasidone Extended Use in Schizophrenia (ZEUS) study. Int Clin Psychopharmacol 2002;17:207-215

60. Keck PE Jr, McElroy SL. Aripiprazole: a partial dopamine D2 receptor agonist antipsychotic. Expert Opin Investig Drugs 2003;12:655-662

61. Stahl SM. Dopamine system stabilizers, aripiprazole, and the next generation of antipsychotics, pt 1: "Goldilocks" actions at dopamine receptors [BRAINSTORMS]. J Clin Psychiatry 2001;62:841-842

62. Potkin SG, Saha AR, Kujawa MJ, et al. Aripiprazole, an antipsychotic with a novel mechanism of action, and risperidone vs placebo in patients with schizophrenia and schizoaffective disorder. Arch Gen Psychiatry 2003;60:681-690

63. Kane JM, Carson WH, Saha AR, et al. Efficacy and safety of aripiprazole and haloperidol versus placebo in patients with schizophrenia and schizoaffective disorder. J Clin Psychiatry 2002;63:763-771

64. Lindsey RL, Kaplan D, Koliatsos V, et al. Aripiprazole and extrapyramidal symptoms [letter]. J Am Acad Child Adolesc Psychiatry 2003;42: 1268-1269

65. Peralta K, Narayanaswamy S, Cohen H, et al. Aripiprazole-induced extrapyramidal symptoms: a case report. Presented at the 7th annual meeting of the College of Psychiatric and Neurologic Pharmacists; April 22-25, 2004; Chicago, Ill

66. Yokoi F, Grunder G, Biziere K, et al. Dopamine D2 and D3 receptor occupancy in normal humans treated with the antipsychotic drug aripiprazole (OPC 14597): a study using positron emission tomography and [11C]raclopride. Neuropsychopharmacology 2002;27:248-259

67. Sajatovic M. Treatment for mood and anxiety disorders: quetiapine and aripiprazole. Curr Psychiatry Rep 2003;5:320-326 